\title{
A criança com deficiência visual em situações de brincadeiras na Educação Infantil
}

\author{
Keuri Costa Carvalhais da Rocha* \\ Erica Aparecida Garrutti-Lourenço **
}

\section{Resumo}

Esta pesquisa investigou a participação da criança com deficiência visual em contextos de brincadeiras na Educação Infantil. Pautou-se na perspectiva histórico-cultural de desenvolvimento humano, de Vigotski, ao considerar que atribui importante papel às relações sociais e as consideram subsídios na construção da brincadeira. $\mathrm{O}$ estudo se efetivou em uma creche de um município da Regiâo Metropolitana da cidade de São Paulo em uma turma de maternal, em que havia uma criança cega matriculada. Pautou-se no caráter qualitativo e se constituiu como estudo de caso, tendo como participantes: uma criança cega, as duas educadoras da turma do maternal, a coordenadora e a vice-diretora da creche. Para a coleta de dados, foi realizada observaçâo simples da rotina dessa turma, essencialmente em relação ao brincar, em dois momentos: março e abril de 2012 e junho de 2012. Os instrumentos de registro foram notas de campo, fotografias e gravaçôes em vídeos. Depois da observação, foram feitas as entrevistas por pautas, tendo como participantes as duas educadoras, a coordenadora e a vice-diretora. Os resultados revelaram que a criança com deficiência visual se utiliza dos seus sentidos remanescentes nos contextos de brincadeiras; a importância de se trabalhar a orientação e mobilidade desde os anos iniciais; e, além disso, a necessidade da atuação do educador como mediador nas situaçóes de brincadeiras para que se potencialize o desenvolvimento integral da criança e principalmente a sua linguagem.

Palavras-chave: Deficiência visual; Inclusão; Brincar.

* Mestranda pela Universidade Federal de São Paulo, Guarulhos, São Paulo, Brasil.

** Professora doutora da Universidade Federal de São Paulo, Guarulhos, São Paulo, Brasil. 


\section{Children with visual disabilities in situations of playing in kindergarten}

\section{Abstract}

This research investigated the participation of children with visual disabilities in the contexts of playing in kindergarten. It was based on Vigotski's historical and cultural perspective of human development as it assigns a role in social relations and considers them a subsidy in the construction of playing. The study was held at a daycare's nursery class in a town of the Metropolitan Region of São Paulo, where there was a blind child enrolled. It was based on the qualitative character and constituted as a case study. The participants were: a blind child, the two teachers of the nursery class, the coordinator and deputy director of the daycare. For data collection, simple observation of this class routine was performed essentially in relation to the playing, on two occasions: March and April 2012; and June 2012. Instruments were recording field notes, photographs and video recordings. After the observation, interviews were held based on staves, having two teachers, the coordinator and the deputy director as respondents. The results revealed that children with visual impairment use their remaining senses in contexts of playing; the importance of work orientation and mobility from the early years; and, moreover, the need for action of the educator as a mediator in situations of playing to leverage the development of children and especially their language.

Keywords: Visual disabilities; Inclusion; To play.

\section{Introdução}

Estudos sobre o brincar e a inclusão escolar de crianças com deficiência se intensificaram nas últimas décadas. Com tal enfoque, esta pesquisa investigou a participação de uma criança com deficiência visual, que integra um grupo de Educação Infantil, em situaçóes de brincadeiras. Para tanto, tem como base teórica a perspectiva histórico-cultural, de Vigotski (1897-1943), ao destacar as relaçôes sociais no processo de constituiçâo humana e, segundo Rocha (1997), explicar como as formas sociais auxiliam a construção de brincadeiras.

$\mathrm{Na}$ idade pré-escolar, surgem tendências e desejos não possíveis de serem realizados imediatamente. Para resolver essa tensão, a criança cria uma situação imaginária - processo psicológico que representa uma forma especificamente humana de atividade consciente e, como todas as funçôes da consciência, surgem originalmente da ação - na qual realiza aquilo que deseja e que na realidade náo poderia fazer concretamente (VIGOTSKI, 2007). Em outras palavras, Fontana e Cruz (1997) explicam, com base na psicologia histórico-cultural, que o mundo objetivo que a criança conhece está continuamente a se expandir e não inclui apenas os objetos que constituem o ambiente da qual faz parte, mas também os objetos com os quais os adultos operam e sobre os quais ela ainda não pode agir. A criança se interessa por uma esfera mais ampla da realidade e sente necessidade de agir sobre ela. Agir sobre as coisas 
é a principal forma que dispõe para conhecê-las e compreendê-las e, nesse sentido, se esforça para agir como um adulto. Portanto, a brincadeira é a forma possível de satisfazer necessidades e desejos em condiçôes diferentes daquelas que ocorrem na realidade, uma vez que possibilita à criança agir como os adultos em uma situaçáo imaginária; essa ação se refere ao brincar de faz de conta.

Fontana e Cruz (1997) e Tunes e Tunes (2001) explicam ainda que a brincadeira possibilita a transição da estreita vinculação entre significado e objeto concreto à operação com significados separados dos objetos, porque, ao agir com um objeto como se fosse outro, a criança separa o significado do objeto real. Nesse sentido, a brincadeira tem papel fundamental no desenvolvimento do pensamento da criança porque, ao substituir um objeto por outro, opera com o significado das coisas e dá um passo importante em direção ao pensamento conceitual. Além disso, quando assume um papel na brincadeira, opera com o significado de sua ação e submete seu comportamento a determinadas regras. Isso conduz ao desenvolvimento da capacidade de fazer escolhas conscientes, que estão relacionadas à capacidade de atuar de acordo com o significado de açôes ou de situaçôes e de controlar o próprio comportamento por meio de regras. No jogo, a criança faz coisas que ainda não consegue realizar no cotidiano e, por isso, o brinquedo cria uma zona de desenvolvimento proximal, pois sempre se comporta além do comportamento habitual de sua idade, ou seja, é como se fosse maior do que é na realidade (VIGOTSKI, 2007). A criação da situação imaginária e a definição das regras específicas do brinquedo contribuem para a constituição da zona de desenvolvimento proximal (OLIVEIRA, 1993). Também na brincadeira de grupo as crianças se relacionam entre si e, no brincar de faz-de-conta, as relaçôes sociais são reproduzidas entre elas (FONTANA; CRUZ, 1997).

A brincadeira é, com base na perspectiva histórico-cultural, a atividade em que ocorrem as mais importantes mudanças no desenvolvimento psíquico da criança e dentro da qual se desenvolvem processos psíquicos que preparam o caminho da transição da criança para um novo e mais elevado nível de desenvolvimento (FONTANA; CRUZ, 1997). A atividade de brincar potencializa o desenvolvimento da criança.

Tendo em vista esses pressupostos, a brincadeira deve permear o trabalho de educadores em creches e pré-escolas com todas as crianças pequenas, independentemente de terem ou não necessidades especiais, como a deficiência visual, que constitui o foco deste estudo.

\section{Percurso metodológico}

Esta pesquisa é qualitativa e descritiva ao considerar que os dados foram coletados em palavras ou imagens e incluíram entrevistas e observaçóes (BOGDAN; BIKLEN, 1994). Essa perspectiva permite o estudo dos participantes em sua cultura; o ambiente natural é a fonte de dados. Ainda, se constitui como um estudo de caso ao permitir o conhecimento de um fenômeno singular dentro de um contexto (GIL, 1999).

Inicialmente, levantou-se uma instituição de Educação Infantil que tivesse uma criança com deficiência visual matriculada e em processo de inclusão, via núcleo 
de apoio à inclusão, de um munícipio da Região Metropolitana da cidade de São Paulo. O referido núcleo solicitou esclarecimentos sobre a pesquisa, realizados via correio eletrônico e, em seguida, disponibilizou o endereço e telefone de uma creche que continha uma criança cega matriculada no maternal (de três a quatro anos de idade). Posteriormente, contatou-se a vice-diretora da instituiçáo para esclarecimentos acerca do estudo e entrega de uma carta com informaçóes referentes à pesquisa. A vice-diretora autorizou sua realizaçáo na creche e, em seguida, foram entregues os termos de consentimento aos participantes: pais da criança cega com três anos de idade, as duas educadoras da turma observada, a vice-diretora e a coordenadora.

Para a coleta de dados, desenvolveu-se a observação simples e entrevistas por pautas (GIL, 1999). Na observação simples, o investigador observa o objeto de investigação e não faz intervençóes. Tendo em vista a necessidade de um controle na obtenção dos dados, foi elaborado um roteiro com a especificaçáo dos aspectos cruciais a serem conhecidos no cotidiano da turma. A observação se concretizou em dois momentos: o primeiro em março de 2012 e o segundo em junho do mesmo ano. As observações foram registradas em notas de campo, filmagens e fotografias, porque esses instrumentos proporcionam a análise detalhada do caso em questáo e, por isso, contribuem para que os dados sejam fiéis à realidade investigada (VIANNA, 2007).

A entrevista por pautas possui certo grau de estruturaçáo, uma vez que se guia por vários aspectos de interesse do investigador. É flexível porque, a cada tema apresentado, o entrevistado pode discorrer livremente e o entrevistador pode intervir quando julgar necessário para que não haja desvio do tema e para a obtenção de dados detalhados. As entrevistas por pautas foram realizadas com as duas educadoras da turma e com as gestoras posteriormente ao período de observação. Para as entrevistas, foram elaborados dois roteiros: um para as educadoras e outro para as gestoras. A elaboração de dois roteiros se fez necessária porque algumas pautas foram direcionadas ao papel das gestoras e outras, ao papel das educadoras. As respostas foram registradas por meio de gravação de voz.

Após a coleta, selecionaram-se os vídeos que apresentavam aspectos relevantes para a pesquisa e, depois, cada episódio foi transcrito minuciosamente, recebendo uma análise articulada com o diário de campo. Vale lembrar que, nessa transcriçáo, os participantes foram identificados com nomes fictícios. As entrevistas foram transcritas e trechos delas discutidos em articulação com os episódios observados.

\section{Resultados e discussão}

Neste tópico, apresentam-se episódios de participação da criança com deficiência visual, Carlos, em situaçóes de brincadeiras na sala de atividades. Os episódios sâo relatados com base nas filmagens e registros complementares do caderno de campo. 


\section{Episódio: $\mathrm{O}$ dia do brinquedo}

As crianças da turma brincam com diversos brinquedos espalhados na sala de atividades. Carlos está no fundo da sala e se arrasta para a sua direita no chão impulsionado pelos movimentos das pernas, aproximando-se de um grupo de crianças. Aline está ao seu lado, ajoelhada no cháo. Ela se abaixa e beija a bochecha de Carlos. Carlos se arrasta em direção ao som de um caminhão de brinquedo que está em sua frente e, nesse momento, é movimentado por uma criança. Ele puxa o caminhão que estava com o colega e se arrasta para frente da sala impulsionado pelos movimentos das pernas, tendo o brinquedo em suas máos (20 segundos). Ainda com o caminhão, se arrasta para o lado esquerdo. Após 15 segundos, encontra um brinquedo no chão, pega-o, joga-o e continua a se arrastar para o lado esquerdo. Ergue seu braço esquerdo - parece querer sentir se chegou próximo da parede. Chega até a parede e encosta nela. Ele permanece com as pernas abertas e o caminhão de brinquedo que pegou do colega está entre elas. Ele toca o brinquedo e arrasta-o no chão. Uma criança se aproxima brincando com outro carrinho e o encosta no caminhão de Carlos. Carlos fala com a criança - as falas não foram compreendidas. A criança se distancia e brinca com o carrinho em outro espaço da sala. Carlos toca as rodas do caminhão, toca a sua parte superior e o arrasta no chão. Depois de trinta segundos explorando o brinquedo com as máos, bate suas mãos em diferentes partes do brinquedo, produzindo um som parecido com o de sua boca. Também, bate no brinquedo e aproxima o ouvido do mesmo. Explora o brinquedo por mais dois minutos. Outra criança se aproxima e fala com Carlos, que parece responder - não foi possível compreender. A criança olha para outros colegas e fala com Carlos novamente. Ela pega nas máos de Carlos que, batendo no caminhão, não deixa o colega tocá-lo. Carlos continua a explorar o brinquedo e a criança continua tentando estabelecer comunicação com Carlos. A criança toca três vezes no caminhão de Carlos e, mais uma vez, tenta falar com ele. Carlos continua a explorar o brinquedo.

Enquanto as crianças brincam e interagem com seus pares, o interesse maior de Carlos se centra em explorar o caminhão de brinquedo, conhecendo-o melhor; arrasta-o por diversas vezes e toca as partes do objeto. O explorar do brinquedo é a sua brincadeira, o que também se apresentou em outras situaçóes. Nesse episódio, Carlos se utiliza, além do tato, da audição, pois, ao produzir sons pelo atrito do objeto com o chão, aproxima os ouvidos do brinquedo. Ele conhece a função do brinquedo, uma vez que o arrasta diversas vezes. Diante desse interesse de Carlos, práticas voltadas para o trabalho com as diferentes sensaçóes - olfativas, táteis, gustativas e auditivas nas brincadeiras e atividades direcionadas pelas educadoras são necessárias de modo a construir mecanismos para a superação da falta da visão. Também é importante que Carlos seja impulsionado a compreender os usos de outros brinquedos, uma vez que manifesta interesse apenas pelo caminhão. 
A tentativa de interação entre as crianças é outro aspecto notado em "O dia do brinquedo". As crianças falam com Carlos que, por sua vez, praticamente não corresponde a essas tentativas de comunicação. No episódio seguinte, é possível analisar como Carlos interage com seus pares, Aline e Claudia, e as educadoras numa situação em que as crianças recebem massinha e palitos de sorvete para livre exploração.

\section{Episódio: Explorando as massinhas}

As crianças estão sentadas no chão da sala de atividades, encostadas na parede e formando um semicírculo. Cada criança recebeu uma massinha e um palito de sorvete. De um lado de Carlos, a Aline está sentada e do outro, a Claudia. Aline chama uma educadora para contar algo: - Tia, o Carlos falou assim: chupeta gostosa. A educadora Daniela responde: - Oxe! A educadora Patrícia diz: - Carlos, você chupa chupeta em casa? Carlos: - Chupo. Aline, Carlos e Claudia continuam com as suas massinhas. Aline e Claudia produzem objetos com a massinha. Carlos balança seu corpo para frente e para trás; fala algumas palavras - não compreendidas pela pesquisadora - e balança novamente o seu corpo. Ele segura a massinha em uma máo e o palito de sorvete em outra. Ele permanece sem manusear a massinha $[\ldots]$

Interrompe-se a gravação por alguns minutos e a filmagem é retomada:

[...] Aline produz sons com a boca e Carlos dá gargalhadas. Enquanto isso, Daniela diz às outras crianças: - Quando é sexta-feira a gente fala assim: para a nossa alegria! As crianças riem e Carlos, nesse momento, movimenta seu corpo para frente e para trás mais rapidamente e sorri também. Aline continua a produzir sons com a boca e Carlos continua a sorrir. Claudia também está sorrindo. De repente, Daniela chama a atençấo das crianças para combinar algo: - Óh, eu vou falar assim: hoje é sexta-feira. Daí quando eu falar, vocês vão falar: Para a nossa alegria! Tá bom!? Tem que falar bem bonito. Daniela continua: - Hoje é sexta-feira. As duas meninas respondem, conforme o combinado: - Para a nossa alegria! Enquanto respondem, riem. Carlos, enquanto a frase é pronunciada, sorri e balança seu corpo $[\ldots]$

A filmagem é novamente interrompida e reiniciada:

[...] Aline produz sons com a boca e Carlos, além de sorrir, produz um som semelhante. Aline aproxima o seu rosto de Carlos que sorri. Em seguida, Aline produz outro som. Dessa vez, ela bate uma mão na boca enquanto pronuncia uma vogal; Carlos dá gargalhadas e balança o seu corpo para frente e para trás.

Primeiramente, há uma rápida conversa entre os sujeitos. Esse é um aspecto importante porque mostra a fala de Carlos e a reposta dele frente à interrogação que lhe é feita. Ao final desse episódio, nota-se a brincadeira com os sons que, dessa vez, 
ocorre pela iniciativa da Aline. Aline faz os sons e Carlos se diverte; logo começa a imitar os sons que Aline produz. Novamente, Carlos se utiliza da audição para imitar os sons produzidos pela Aline e esse aspecto confirma o interesse da criança com deficiência visual pelos sons que a rodeiam. No decorrer do episódio, é nítido o vínculo de Carlos com Aline, o que também ocorre em "O dia do brinquedo", quando ela o beija. Há uma interação que proporciona momentos de alegria e, certamente, de aprendizagem.

Em entrevista, a educadora Patrícia informa as contribuiçóes proporcionadas pela interação entre pares.

Ah! Eu acho que é riquíssima essa, essa interação porque cada criança tem uma vivência. Elas vêm de famílias diferentes, apesar de estarem inseridas no mesmo bairro, mas cada família tem uma maneira de conviver, de criar, no caso, as crianças. Eu acho interessante, que eles trocam vivências [...] Eu acho interessante nesse sentido, que eles trocam [...].

Comenta que a interação entre pares contribui sobremaneira com o desenvolvimento de Carlos:

[...] eu acho que isso pra ele também é muito rico, por conta que, às vezes, no mundo da casa dele, é só ele. É só ele, o pai e a mãe, no caso a avó ou algum primo que, de vez em quando, vem e pra ele esse contato eu acho rico pra ele descobrir que existem outras pessoas além da família, que ele vai conviver durante na vida dele [...] Eu acredito que é riquíssima mesmo por conta da convivência que é algo pra ele natural... que ele não vai achar estranho, como se, vamos supor, no caso ele só fosse pra escola com sete ou seis anos.

A fala da educadora aponta para a importância da interação entre todas as crianças, inclusive Carlos. O desenvolvimento pleno do ser humano depende do aprendizado que se constitui na interação com outros indivíduos. A interação entre as crianças se dá, essencialmente, por meio da fala e esta tem o contato social como função fundamental (REGO, 2012). No início desse episódio, Carlos fala de modo compreensível com Patrícia. Entretanto, em "O dia do brinquedo" e no trecho seguinte, as falas de Carlos nem sempre são claras.

\section{Brincando com pecinhas}

Alguns brincam sozinhos e outros em pequenos grupos. Carlos balbucia algumas palavras - não compreendidas pela pesquisadora. Ele também bate suas mãos no chão de modo a alternar uma mão e outra.

Nota-se, nos episódios anteriores, que a fala de Carlos requer uma atenção especial, uma vez que nem sempre é compreensível e regular. A relação entre o pensamento e a fala passa por diversas mudanças ao longo da vida do indivíduo. O balbucio de um bebê, o seu choro, são falas primitivas, mas sociais; cumprem a função de alí- 
vio emocional (REGO, 2012). Posteriormente, a criança demonstra uma capacidade de agir no ambiente para solucionar alguns problemas, por exemplo, resolver como se pode pegar um objeto que está em um local alto. Por meio do diálogo com pessoas que dominam a linguagem, a criança aprende a usar a linguagem como instrumento de pensamento e meio de comunicação, como explana Rego (2012), ao mencionar sobre a teoria de Vigotski. Nesse sentido, o Referencial Curricular Nacional para a Educaçâo Infantil (BRASIL, 1998) explicita que as instituiçốes de Educação Infantil devem organizar suas práticas a fim de que as crianças participem de diversas situaçôes de comunicação oral para interagir e expressar desejos e necessidades.

Para a criança com deficiência visual, devem ser criadas condições em que as falas com as quais tenha contato sejam relacionadas com os respectivos significados. A fala de Carlos será mais desenvolvida e clara nas interaçóes principalmente com a mediação de adultos nos diferentes momentos da rotina. A mediação é indispensável para o conhecimento de mundo da criança cega e para o desenvolvimento de sua fala, uma vez que se dá por meio da linguagem oral.

A orientação e mobilidade é outro aspecto notado nos episódios. Ele se move com segurança por todo o espaço. Enquanto as crianças, em geral, brincam com seus brinquedos, como em "O dia do brinquedo", interagindo entre si, Carlos se arrasta pelo espaço da sala de atividades, por meio do uso de seus sentidos remanescentes para compreender as açóes que ocorrem naquele ambiente, buscar o seu brinquedo preferido, ou até mesmo brincar com o espaço, pois frequentemente se arrasta pelo chão.

O conhecimento do espaço se trata de uma das aprendizagens mais complexas para a criança com deficiência visual (OCHAÍTA; ESPINOSA, 2004). Isso porque não possui uma visáo total ou parcial que lhe permita se locomover com segurança nos diferentes espaços frequentados por ela, como explicam Garcia e Machado (2006). Por isso, favorecer o desenvolvimento da orientação e mobilidade da criança com deficiência visual é importante desde a Educação Infantil, já que a partir dessa etapa a criança vivenciará diferentes situaçôes que envolverão jogos e brincadeiras em grupo.

A mobilidade de Carlos é mencionada nas entrevistas, especificamente em relação aos avanços observados ao longo do primeiro semestre de 2012. Nesse sentido, Patrícia comenta:

Ele era inseguro pra fazer. Ele, hoje [...] já faz com desenvoltura [...]. Antigamente, ele tinha necessidade de alguém ficar em cima dele [...] Ele não ia se você não pegasse na máo [...]. Hoje ele até recusa um pouco a ajuda de algumas crianças que tentam ajudar. [...] Ele já se sente familiarizado com o local. [...] No dia da festa junina [...] ele foi rodando com as outras professoras e até sozinho pra outras salas. 
A coordenadora diz que nota a confiança no caminhar, favorecida pelo acompanhar as crianças pelo barulho que elas fazem e uso do tato, pontos esses que se apresentaram nas observaçóes. A vice-diretora informa que Carlos conhece a estrutura da escola. Segundo Daniela, a autonomia dele melhorou bastante e que, por isso, não é mais táo dependente das educadoras e dos amigos. Desse modo, a mobilidade de Carlos é bem desenvolvida.

Há, ainda, outro episódio que nos permite conhecer o manuseio de pecinhas, como lego, por Carlos. A brincadeira com peças de montar é um convite para a exploração e imaginação, porque permite a construção de inúmeros objetos e, como afirmam Fontana e Cruz (1997), possibilita o relacionamento entre as crianças quando realizada em grupo.

\section{Episódio: Arrastando a pecinha no cháo}

[...] Carlos pega as peças do lego. Dentre elas, encontra uma pequena placa verde e a toca. Depois, coloca a placa na boca, vira-a e coloca-a na boca novamente. Em seguida, um colega que está ao lado de Carlos pega a placa. Carlos tenta alcançá-la e, para isso, passa as mãos no chão e tenta tocar o colega. Após algumas tentativas, desiste e pega uma de suas pecinhas e a arrasta no chão diversas vezes com força, provocando um ruído. Rapidamente a educadora Daniela pede para ele parar. Carlos pára e toca outras pecinhas. Em seguida, pega novamente a peça que estava arrastando no chão e a arrasta mais uma vez, fazendo um forte ruído.

Carlos parece não saber o que fazer com as peças. Às vezes, ele age como se as peças fossem carrinhos, mas logo as abandona. Particularmente, demonstra certa irritação quando um colega lhe toma a peça que segurava e, então, arrasta outra peça com força no chão, provocando um forte ruído. Esse episódio aponta para a necessidade de as educadoras atuarem como mediadoras, de modo a explorar possibilidades diversas de brincar e a explicar a função do brinquedo, pois Carlos não constrói objeto algum, o que se repetiu em outras situaçóes de brincadeira com pecinhas de montar.

Em relação ao brincar de faz de conta, comum entre as crianças do maternal, mostra-se ausente nas brincadeiras de Carlos. Vários episódios observados de brincadeiras de faz de conta durante a coleta de dados são constituídos apenas por crianças videntes. Pondera-se que cada criança se desenvolve de modo diferente, entretanto, deve haver uma atenção das educadoras em relação a tal ausência. Isso porque no brincar de faz de conta a criança se utiliza das compreensóes que possui acerca da realidade em que está inserida e, além disso, potencializa o desenvolvimento psíquico (FONTANA; CRUZ, 1997) e cria a zona de desenvolvimento proximal (VIGOTSKI, 2007). "É no jogo das relaçôes da criança com os adultos e com as outras crianças, dado o lugar social que ocupa na rede social que a envolve, que emerge, evolui e se transforma a brincadeira infantil do faz-de-conta, dando lugar ao jogo com regras em que há a supremacia da palavra" (TUNES; TUNES, 2001, p. 85). 
Reconhecer as peculiaridades da criança com deficiência visual é uma necessidade para que se intervenha em diversos momentos da rotina da turma até mesmo no brincar.

\section{Considerações finais}

Os resultados revelaram que a brincadeira da criança com deficiência visual depende do modo como compreende o ambiente e o explora, utilizando de seus sentidos remanescentes, principalmente do tato e da audição e, em alguns momentos, do paladar, ao colocar objetos na boca. Carlos explora os brinquedos de diferentes maneiras, geralmente por atritos que emitem diferentes sons, sendo que nesse explorar aproxima o seu ouvido dos brinquedos/objetos. Essa exploraçáo realizada por Carlos aponta ainda para a possibilidade de um trabalho pedagógico que enfatize a exploração dos diversos sentidos sensoriais pelas crianças da turma criando, desse modo, uma sensibilizaçáo por proporcionar outras possibilidades de perceber, conhecer e sentir o mundo que as rodeiam, tendo a linguagem como direcionadora central desse processo.

As interaçóes entre a criança com deficiência visual e seus pares pela linguagem oral em brincadeiras ocorrem sutilmente. Algumas crianças tentam interagir com Carlos em alguns momentos, mas nem sempre são correspondidas. Essa interação entre Carlos e as demais crianças, que ocorre tão pouco, revela a necessidade do planejamento de propostas que valorizem brincadeiras conjuntas, para que a criança com deficiência visual possa criar vínculos com o coletivo de crianças de sua turma. Não se trata apenas de compor os grupos, mas de realizar mediaçôes que favoreçam trocas entre as crianças, contribuindo para a comunicaçáo oral entre elas e para o desenvolvimento da linguagem.

Em relação à orientação e mobilidade, Carlos se move com segurança nos espaços da sala de atividades e o seu desenvolvimento nesse aspecto é comentado pelas entrevistadas. A orientação e mobilidade pode ser trabalhada por meio de brincadeiras desde a Educação Infantil, contribuindo cada vez mais para a liberdade de locomoção pela criança com deficiência visual nos diversos ambientes que frequenta.

Os dados também evidenciam a necessidade de intervenção pelas educadoras nas brincadeiras, de modo que a criança com deficiência visual não brinque apenas com um brinquedo/objeto, por exemplo, o carrinho e/ou caminhão, mas de modo que o seu universo seja ampliado, e que seja proporcionado o enriquecimento das brincadeiras com peças e a criação de situações imaginárias que possam resultar em brincadeiras de faz de conta, potencializando o desenvolvimento da criança em vários aspectos, principalmente, sua linguagem.

Por fim, destaca-se que as especificidades e as potencialidades da criança com deficiência visual devem ser atendidas e consideradas durante todo o processo educacional, inclusive em situaçóes de brincadeiras para que essa criança possa participar efetivamente de todas as atividades que compóem a rotina de sua turma. 


\section{Referências}

BOGDAN, R.; BIKLEN, S. Investigaçáo qualitativa em educaçáo: uma introduçáo à teoria e aos métodos. Portugal: Porto, 1994.

Ministério da Educação e do desporto. Referencial curricular nacional para a educaçáo infantil. v. 1, Brasília: MEC, SEF, 1998.

FONTANA, R.; CRUZ, N. Psicologia e trabalho pedagógico. São Paulo: Atual, 1997.

GARCIA, N.; MACHADO, E. V. Orientação e mobilidade na educação infantil. In: BRUNO, M. M. G. (elaboração) et al. Educaçáo Infantil: saberes e práticas da inclusão: dificuldades de comunicação sinalização: deficiência visual. 4. ed. Brasília: MEC/SEESP, 2006.

GIL, A. C. Métodos e técnicas de pesquisa social. 5. ed. São Paulo: Atlas, 1999.

OCHAÍTA, E.; ESPINOSA, M. Á. Desenvolvimento e intervenção educativa nas crianças cegas ou deficientes visuais. In: COLL, C.; MARCHESI, Á.; PALACIOS, J. (Org.). Desenvolvimento psicológico e educaçáo: transtornos de desenvolvimento e necessidades educativas especiais. Trad. Fátima Murad. v. 3, 2. ed. Porto Alegre: Artmed, 2004

OLIVEIRA, M. K. Brinquedo e desenvolvimento. In: processo sócio-histórico. São Paulo: Scipione, 1993.

Vygotsky: aprendizado e desenvolvimento, um

REGO, T. C. Vygotsky: uma perspectiva histórico-cultural da educaçăo. Petrópolis: Vozes, 2012.

ROCHA, M. S. P. M. L. O real e o imaginário no faz-de-conta: questóes sobre o brincar no contexto da escola. In: SMOLKA, A. L. B. e GÓES, M. C. R. A significaçáo nos espaços educacionais: interação social e subjetivação. Campinas: Papirus, 1997.

TUNES, E.; TUNES, G. O adulto, a criança e a brincadeira. Em aberto. Brasília, v. 18, n. 73, p. 78-88, julho. 2001.

VIANNA, H. M. Pesquisa em educação: a observação. Brasília: Liber Livro Editora, 2007.

VIGOTSKI, L. S. O papel do brinquedo no desenvolvimento. In: A formaçáo social da mente. São Paulo: Martins Fontes, 2007.

\section{Correspondência}

Keuri Costa Carvalhais da Rocha - Rua Virginia Germano, 61 - Jardim Iguatemi. CEP: 08370-330. São Paulo - São Paulo, Brasil.

E-mail: keuricarvalhais@gmail.com - egarrutti@yahoo.com.br

Recebido em 15 de julho de 2014

Aprovado em 04 de novembro de 2014 